\title{
Phenomenology, Naturalism and the Sense of Reality
}

\section{Matthew Ratcliffe}

\begin{abstract}
Phenomenologists such as Husserl, Heidegger and Merleau-Ponty reject the kind of scientific naturalism or 'scientism' that takes empirical science to be epistemologically and metaphysically privileged over all other forms of enquiry. In this paper, I will consider one of their principal complaints against naturalism, that scientific accounts of things are oblivious to a 'world' that is presupposed by the intelligibility of science. Focusing principally upon Husserl's work, I attempt to clarify the nature of this complaint and state it in the form of an argument. I conclude that the argument is effective in exposing naturalism's reliance upon impoverished conceptions of human experience, and that it also weakens the more general case for naturalism.
\end{abstract}

\section{Introduction}

The aim of this paper is to assess the effectiveness of a criticism of naturalism, voiced by several philosophers in the phenomenological tradition. I will focus exclusively upon Husserl, Heidegger and Merleau-Ponty, although others have also made much the same claim: that empirical science and - consequently - scientific naturalism obliviously presuppose rather than succeed in describing the everyday 'world'. The term 'naturalism' is used to refer to a wide range of doctrines, any one of which might be compatible or incompatible with phenomenology for various different reasons. For current purposes, it refers to a philosophical position concerning the relationship between human experience and scientific accounts of the world. According to this position, which is sometimes labelled 'scientism' by critics, the empirical sciences are metaphysically and epistemologically privileged over all other forms of enquiry. ${ }^{1}$ Hence the best account of reality we have is provided by science, and anything we take to be real should be coherently integrated into that account. ${ }^{2}$ It is not entirely clear what is and is not metaphysically acceptable, given that current science is incomplete and that, even if we grant the possibility of a complete science, we do not know what it would look like. It is also unclear which epistemic practices are to be awarded privileged status, as the empirical sciences employ a range of different methods. However, despite the gray areas, an intuition that unites naturalists of this persuasion is that

\footnotetext{
${ }^{1}$ See, for example, Dupré (2001) for a critique of scientism.

${ }^{2}$ For a very different formulation of naturalism, which is not - in my view - vulnerable to the kind of phenomenological criticism that I consider here, see, for example, Rouse (2002).
} 
phenomenological descriptions do not fit the bill. If what phenomenologists study is real, understanding it requires somehow integrating it into a picture of the world supplied by sciences such as neurobiology.

Some naturalists maintain that the work of Husserl and his successors is philosophically valuable, in so far as phenomenologists have provided descriptions of experience that are more detailed and accurate than anything available elsewhere. So we need not dismiss the phenomenological tradition altogether. We can instead disregard its anti-naturalism and treat it as a source of phenomenological data. In other words, phenomenology can supply the explananda for naturalistic explanations of human experience. For instance, Roy, Petitot, Pachoud and Varela (1999, pp.1-2) insist that fruitful interaction between phenomenology and science ultimately requires naturalisation of the former, "even though Husserl himself strongly opposed naturalism", where naturalisation is understood as integration "into an explanatory framework where every acceptable property is made continuous with the properties admitted by the natural sciences". The phenomenologists would agree, up to a point. That they oppose naturalism does not make them 'anti-science', and they are not. Husserl, in texts such as Cartesian Meditations, stresses that one of the primary tasks of phenomenology is to provide a secure philosophical foundation for science. Phenomenological research can also be informed by empirical science. For example, Merleau-Ponty's Phenomenology of Perception makes use of findings that would these days be termed 'neuropsychological'. In more recent years, there has been increasing dialogue between phenomenology and the neurosciences, as exemplified by the arrival of the journal Phenomenology and the Cognitive Sciences in 2001. With this, there is growing acknowledgement that interaction between the two can be mutually enlightening, and several different views of the relationship have been offered. ${ }^{3}$

Hence I think it is right to endorse what might be called a 'weak' form of naturalism, according to which there is a degree of continuity between phenomenology and science; they interact in various ways and have a subject matter that is - to some extent - shared. Husserl's phenomenological method is quite different from empirical scientific methods. But, then again, science includes many different methods, and 'continuity' between them surely does not imply an inability to distinguish them. The phenomenological tradition likewise

\footnotetext{
${ }^{3}$ See Gallagher and Zahavi (2008, Chapter 2) for a good summary of views concerning the relationship between phenomenology and cognitive science.
} 
encompasses various methods, most of which diverge significantly from Husserl's. Thus, methodological differences between phenomenology and science do not prohibit the view that there is continuity between the two. What Husserl, Merleau-Ponty and Heidegger certainly do object to though is the view that science has a kind of priority over phenomenology, that discoveries made through phenomenological methods are metaphysically acceptable only once naturalised. Now, naturalism need not incorporate dogmatic, unwavering commitment to the view that there is no more to the world than what empirical science can reveal. One advocate of a more modest naturalism is Dennett (1987, p.5), who regards the view as a "tactical choice" or "starting point"; it might turn out to be wrong, but it looks like a good bet at the moment. However, the criticism that I focus upon here is equally opposed to that view. The concern is not that something might be missing from a naturalistic view of the world and that acceptance of naturalism ought therefore to be tentative. The phenomenologists complain that something is missing, and that the naturalistic hunch - however cautious it might be - is therefore misguided. In what follows, I will attempt to clarify and then assess their complaint that naturalism overlooks the 'world'.

\section{Science and the World}

Phenomenologists have made a range of claims to the effect that science is ignorant of its own conditions of possibility and thus its limitations. For example, Husserl's project of providing a firm foundation for science is motivated by the concern that sciences are hampered by "obscurities in their foundations, in their fundamental concepts and methods" (1960, p.4). Amongst other things, he maintains that scientific accounts of the world operate with historically and culturally inherited metaphysical presuppositions, which have been forgotten by scientists and by philosophers (Husserl, 1960, 1970). Heidegger similarly claims that the empirical sciences rely upon implicit "basic concepts", which shape scientific accounts of the world in unacknowledged ways. According to Heidegger, real scientific progress happens when these basic concepts are revised in ways that involve their becoming explicit (1962, pp.29-30). Elsewhere, he puts the point more strongly, remarking that "science is dogmatic to an almost unbelievable degree everywhere, i.e. it operates with preconceptions and prejudices [which have] not been reflected upon" (Heidegger, 2001, p.103). Both philosophers add that the sciences are not just metaphysically naïve. The problem, they suggest, is equally about blinkered attitudes. Husserl raises concerns about what he calls the "naturalistic attitude" of scientific enquiry, which is - he says - limited in what it is able to grasp. Furthermore, it is oblivious to those limitations: "As long as we live 
in the naturalistic attitude, it itself is not given in our field of research; what is grasped there is only what is experienced in it, what is thought in it, etc" (Husserl, 1989, p.183). He contrasts this with the "personalistic" attitude of everyday life, where we respond to others as persons by spontaneously engaging with them in various ways, and where we also take "the things surrounding us precisely as our surroundings and not as 'Objective' nature, the way it is for natural science" (Husserl, 1989, p.192). Hence the personalistic attitude, Husserl maintains, reveals aspects of people and of the world more generally that are inaccessible to the objective, impersonal approach of empirical science. Heidegger (1962, Division One, III) similarly contrasts scientific attitudes to things with everyday practical attitudes, in drawing his well-known distinction between encountering things as present-at-hand [Vorhanden] and as ready-to-hand [Zuhanden]. In brief, the former involves approaching an entity in a detached, theoretical way, epitomised by the scientific gaze, whereas the latter involves a practically engaged, non-reflective appreciation of things, as when one uses a pen to write. Like Husserl, Heidegger claims that the more theoretical attitude misses something that the practically engaged attitude is open to. So the general charge is that science is ignorant of its own limitations, something that can be put right through phenomenological clarification of its presuppositions. This charge applies equally to naturalism, a doctrine that is symptomatic of that ignorance.

A closely associated but further-reaching criticism of naturalism appears, in slightly different forms, in the works of Husserl, Heidegger, Merleau-Ponty and others. Naturalism is charged with being ignorant, not merely of some feature of the world, but of the world. The world of everyday experience, it is maintained, is not incorporated into the scientifically described world, even though the latter's intelligibility tacitly depends upon the former. Heidegger, for instance, states that the kind of 'knowing' that characterises scientific enquiry presupposes "Being-in-the-world" (1962, p.90). Science, he suggests, not only fails to adequately characterise how we find ourselves in the world; it fails to even acknowledge the existence of a world that both science and everyday life take for granted. Husserl likewise maintains that empirical science and thus naturalism have 'forgotten' the world that science is rooted in. For example, he claims that, even as early as Galileo, we find "the surreptitious substitution of the mathematically substructed world of idealities for the only real world, the one that is actually given through perception" (1970, pp.48-9). This, he adds, was then passed on to Galileo's successors, right up to the present. For Husserl, scientific conceptions of things are useful abstractions, but their status as abstractions has been forgotten and they have come to replace 
the world that they depend upon. The process is analogous to our using a map to navigate and then coming to think of the relevant terrain solely in terms of the map. Merleau-Ponty similarly calls for reflection upon a world that scientific enquiry rests upon and fails to describe:

To return to things themselves is to return to that world which precedes knowledge, of which knowledge always speaks, and in relation to which every scientific schematization is an abstract and derivative sign-language, as is geography in relation to the countryside in which we have learnt beforehand what a forest, a prairie or a river is. (1962, ix).

What are we to make of such remarks? Those who are opposed to the phenomenologists' position are unlikely to be moved. Even if science is contingently ignorant of some of its presuppositions, it is not necessarily ignorant. There is nothing to prohibit reflection upon and critique of "basic concepts" as an accompaniment to or even constituent of scientific methods. Science could strive for basic concepts that are better, according to some agreed standard (Wheeler, 2005, pp.126-7). More generally, failure to reflect upon scientific history and culture is not something that science insists upon. So these allegations might be regarded as - at most - contingently true. In addition, failure to explicitly grasp all of one's presuppositions is surely not specific to science. Indeed, it is arguable that all other forms of enquiry are just as guilty. So this criticism does not constitute an objection to the view that scientific practices are privileged according to some other criterion. As for the charge that science incorporates a blinkered theoretical stance that shuts out certain aspects of the world, one might be tempted to dismiss this as a caricature. It is not at all clear that empirical science is strait-jacketed by a single 'stance' or 'attitude' that characterises all forms and all stages of enquiry in all domains. Consider, for example, the roles that are arguably played by emotional attitudes towards one's subject matter. Thagard (2002) documents how topic selection, investigation, discovery and justification are all regulated by a range of emotions, including wonder, excitement, awe, anxiety and aesthetic feelings. Whatever else one might say here (and there is a great deal more to be said), scientific enquiry surely accommodates various different attitudes. Furthermore, acknowledging what is revealed to many different perspectives, attitudes and practices is quite compatible with then attempting to assimilate all of it into a metaphysical picture that is derived from only a subset of them. So the naturalist's metaphysical embargo cannot be swiftly dismissed on that basis that it involves naïve acceptance of what is delivered via a clearly-defined and restrictive scientific attitude, stance 
or gaze. Of course, the attitude of the naturalist might not be the same as that of the scientist. However, the criticism of naturalism is that it is insensitive to certain limitations of science, and the naturalist can respond by maintaining that science is not limited in these ways.

What about the criticism that science, and thus naturalism, obliviously presuppose 'the world'? One problem is that it is not at all clear what is meant by 'world' in this context. 'World', as others have noted, is a slippery term, which is used in all sorts of different and often vague ways (van Fraassen, 2002). Hence an obvious strategy for the naturalist is to simply dismiss this talk of world as empty gesturing: science describes the world - what other 'world' is there? However, I will suggest in what follows that much of what the phenomenologists say about 'world' can be clarified and couched in the form of an argument, an argument that has at least some plausibility. What naturalism fails to acknowledge, and what phenomenologists at least sometimes refer to as the 'world', is a neglected aspect of experience that I will call the 'sense of reality'. The position I sketch is - very roughly Husserl's, although I will present it with a degree of abstraction that renders it equally compatible with much of what Heidegger and Merleau-Ponty say.

\section{The Sense of Reality}

In this section, I will attempt to characterise the 'world' of the phenomenologists, which scientific naturalism is allegedly oblivious to, in the following five steps:

a. Taking something to be real presupposes a sense of reality.

b. The 'world' consists, at least in part, of this sense of reality.

c. We experience possibilities.

d. To have a sense of reality is to experience oneself as inhabiting a possibility space.

e. This possibility space (and thus the 'world') is presupposed by the scientifically described world.

First of all what is a 'sense of reality'? Consider the experience of seeing a cat in front of you - what from does the appreciation that 'a cat is present' take? Taking it to be the case that a cat is present is not a matter of assenting to the truth of a proposition on the basis of a prior perception. Instead, it at least seems that you are perceptually presented with an entity of the kind 'cat', and that the perceptual experience incorporates a sense of the entity as there. Taking it to be the case that the cat is there is phenomenologically distinct from imagining it, 
doubting that it is what it appears to be, being uncertain of its presence, anticipating its presence, and so on. If you lacked the ability to distinguish between taking something to be the case and these other possibilities, you would be unable to take anything to be the case or not the case. And what I refer to as the 'sense of reality' is the ability to grasp such distinctions, to find them intelligible. So it is not simply the taking of certain things to be there or, more generally, real. Rather, it is presupposed by the possibility of doing so. Of course, a sense of something's being the case is not limited to perceptual experience; we also have non-perceptual beliefs. I regard perceptually taking $p$ to be the case as a form of 'belief'. However, even if one were to claim that taking something to be the case (perceptually or otherwise) is not sufficient for belief (perhaps, in addition, one needs to take $p$ to be true), it is surely necessary for belief. If we had no grasp at all of what it is for something to be or not be, we could not believe anything; an attitude of belief would be unintelligible to us. Although a sense of something's being the case is not exclusive to perceptual experience, I will take perceptual experience as a starting point for reflecting upon it and articulating its structure. In the process, it will become clearer how a sense of reality can indeed be integral to perceptual experience, just as brief reflection upon the phenomenology of perception suggests that it is.

The next step is to acknowledge the sense of reality as a phenomenological achievement. Doing so is central to the attitudinal shift that Husserl calls the "phenomenological reduction". According to Husserl, when we experience or think about something, we ordinarily do so from within an already given world. When we take something to be present, imagine it or remember it, we take that world for granted as a backdrop to our experiences and thoughts. It is not itself the object of some attitude, but a context in which we adopt various kinds of attitude towards states of affairs. The phenomenological reduction involves ceasing to take the world for granted and instead making it an explicit object of philosophical study. Importantly, it is not merely about explicitly reflecting upon something we more usually implicitly take to be the case. The world, in this sense, is presupposed by our taking anything to be the case or otherwise. Hence Husserl's 'world' consists - at least in part - of what I have called the 'sense of reality'. One need not accept the specifics of Husserl's method in order to appreciate this general methodological orientation. Indeed, we find it in 
Heidegger and Merleau-Ponty too, despite the fact that their work parts company with Husserl in other important ways. ${ }^{4}$

One might be tempted to simply reject the claim that we have a phenomenological 'sense of reality' or 'world', on the basis either that there is no such thing or that its nature is irretrievably vague: what is it supposed to consist of - an indefinable 'quale' that most of us haven't even noticed? So what is needed is a clear and defensible statement of what the sense of reality consists of. We can develop this by starting from Husserl's characterisation of perceptual experience. According to Husserl, when you look at an entity such as a chair, what you see is 'a chair', even though only parts of it are perceptually available to you at the time. A type of object is "naturally and simply there for us as an existing reality as we live naively in perception" (Husserl, 2001, p.35). You experience it as an entity of a certain kind that is here now, as opposed to experiencing some other content, inferring it to be an appearance of a chair and then inferring a chair to be present here and now. Husserl maintains that doing so involves experiencing the possible as well as the actual. When an entity is perceived, the experience incorporates a structured system of possible perceptions and activities involving that entity:

Everywhere, apprehension includes in itself, by the mediation of a 'sense', empty horizons of 'possible perceptions'; thus I can, at any given time, enter into a system of possible and, if I follow them up, actual, perceptual nexuses. (1989, p.42)

This "horizon" of possibilities is implicated in what Husserl calls "passive synthesis", our effortlessly perceiving enduring entities, rather than a chaos of changing appearances that we have to piece together with effort. Importantly, we perceive various different kinds of possibility. For example, seeing an entity such as a glass incorporates a sense of what we would see if we looked at it from another angle. What is anticipated can be more or less specific. It might take the form 'move that way way to reveal a clear, curved surface' or 'move that way to reveal a colour and texture, which are currently eclipsed'. Husserl also stresses that the possibilities we perceive are inter-sensory. For instance, visual appearances can incorporate tactual possibilities (Husserl, 1989, p.75). As Merleau-Ponty similarly says, the perceived thing is an "inter-sensory entity"; "any object presented to one sense calls upon

\footnotetext{
${ }^{4}$ See, for example, Merleau-Ponty (1962, xiii-xiv) for a discussion of the reduction in his own work, along with that of Husserl and Heidegger.
} 
itself the concordant operation of all the others" (1962, pp.317-8). Consider how you might see a sharp knife glistening in the sun and almost feel its potential to slide across your hand and cut you.

However, Husserl does not restrict the phenomenology of possibility to the realm of potential perceptions. Perceptual possibilities imply a sense of what one would have to do in order to perceive something. The relevant activities do not always take the form 'I could do $p$ '. There is a distinction between merely 'open' possibilities and others that are 'enticing'. The latter not only present $p$ as a possibility; they draw us in with varying degrees of "affective force" (2001, pp.83-91). Husserl refers to of "the allure give to consciousness, the peculiar pull that an object given to consciousness exercises on the ego", the way it beckons us to actualise perceptual possibilities in a certain way (2001, p.196). Doing so requires bodily activities such as moving one's head in order to reveal an eclipsed surface. Now, the bodily movements that are solicited by an entity in order to further perceive it (which Husserl calls 'kinaestheses') are to be distinguished from goal-directed, practical actions. Even so, the kinds of possibility that entities are perceived to offer surely reflect our various practical concerns, dispositions and capacities too. The theme of experienced practical significance is more often associated with Heidegger's work than Husserl's. Nevertheless, Husserl similarly appreciates that:

In ordinary life, we have nothing whatever to do with nature-Objects. What we take as things are pictures, statues, gardens, houses, tables, clothes, tools, etc. These are all value-Objects of various kinds, use-Objects, practical Objects. They are not Objects which can be found in natural science. $(1989$, p.29)

How something is significant to us, how it 'matters' to us, is at the same time a sense of the possibilities that it has to offer. Once this is acknowledged, the range of possibilities that we are receptive to expands considerably, given that things appear to us as significant in a range of different ways. Something might be practically significant in the context of some project, or perhaps threatening to us. Broad categories of mattering such as these can be subdivided. Something can appear practically significant in so far as it is urgently required, appropriate for a task, inappropriate, cumbersome, obstructing activity and so on, and a threat might be major, minor, likely, unlikely, inevitable, distant or imminent. In addition, there is a distinction to be drawn between possible activities and possible happenings, between 'I can 
actualise $p$ ' and ' $p$ might happen'. An important complication is that possibilities present themselves not simply as 'for me' but for others too (Husserl, 1960, Fifth Meditation). A chair appears to me as something that I and others might access perceptually and practically in various ways. To add to the phenomenological complexity, kinds of significant possibility such as threat further subdivide into 'threatening to us', 'threatening to me but not for them', 'threatening to you but not for me', and so on. Furthermore, interpersonal relations open up new kinds of possibility, including communion, estrangement, practical assistance, and distinctively interpersonal forms of threat.

Perceived possibilities are not phenomenologically isolated. Rather, they interrelate in dynamic and structured ways so as to comprise "entire indicative systems, indications functioning as systems of rays that point toward corresponding manifold systems of appearance" (Husserl 2001, p.42). As certain possibilities are actualised, others are revealed, and the process proceeds in a structured fashion. Experience, Husserl suggests, is structured by modes of practical, non-conceptual anticipation. In the context of habitual activity, we for the most part - anticipate the coming of something as certain (Husserl, 2001, p.91). As I walk along the street, I take it as given that my foot will again meet with flat, hard ground; no other possibilities have any allure. The presence of such expectations is made salient by those occasions when they are disappointed. There might be surprise, a sense that something is not as expected or a feeling of unfamiliarity, despite the absence of any specific, conceptualised expectation regarding what might happen next. But possibilities can also present themselves as doubtful or uncertain. The dynamic interplay of different kinds of anticipation constitutes our sense of what something is, along with our sense that it is, both of which feature in perception with varying degrees of confidence.

Husserl supplements his account of horizons with the view that our experience of possibilities is inextricable from our bodily phenomenology. Certain bodily dispositions are, at the same time, a sense of the perceptual and practical possibilities offered by our surroundings. The body $[$ Leib] is not only an entity within the experienced world but also that through which we experience the world, it is "the medium of all perception; it is the organ of perception and is necessarily involved in all perception" (Husserl, 1989, p.61). Drawing on Husserl, MerleauPonty likewise maintains that "the body is our general medium for having a world" (1962, p.146). It is not merely an object of perception and thought but that through which we are open to systems of worldly possibilities. 
However, for current purposes, my primary concern is not with whether or how perception of possibilities might relate to bodily experience. What is of interest is the view that we do indeed perceive various kinds of possibility, which are integral to our sense of what things are, along with our sense that they are. I concede that the view requires further development and defence. For example, there is a lack of clarity regarding where and how the distinction between perceptual and non-perceptual content should be drawn or, indeed, whether it should be drawn at all. Here, phenomenology would benefit from greater interaction with recent work in the philosophy of mind on the nature of sensory perception and perceptual content. ${ }^{5}$ There is a degree of convergence between Husserl's view and what at least some philosophers of mind are currently saying. For instance, O’Callaghan (2011; forthcoming) maintains that perception has a rich inter-modal structure and that perception through one sense incorporates an appreciation of what else could be perceived through that and other senses: "You hear a sound as the sound of something that could be seen of brought into view, and that has visible features" (2011, p.157). Consideration of such work might well help to clarify, fine-tune and/or further support the Husserlian conception of content.

So I do not wish to suggest that we simply accept Husserl's account of perceptual horizons. Nevertheless, I do think it is both clear enough and phenomenologically plausible enough to be taken seriously. How, though, do we get from the horizonal structure of entities that are experienced as residing in a world to 'the world' itself? There is one more move to be made, which I think we find in the work of Husserl and Merleau-Ponty, and in a slightly different form in Heidegger, although none of them state it explicitly. That move is to distinguish between types of possibility such as 'threat' and 'perceptual accessibility', and tokens of those types, such as ' $x$ has threatening property $p$ ' or ' $y$ can be accessed perceptually by moving my head'. The possibilities that contribute to our sense of the nature and existence of a particular entity are token possibilities. However, if we did not have access to the relevant types of possibility, such as threat and practical significance, we would not be able to experience any entity as threatening or practically significant in any way. The 'world' that is presupposed by scientific accounts of things is comprised of an openness to the various types of possibility. When we experience something as threatening, perceptually accessible,

\footnotetext{
${ }^{5}$ See, for example, MacPherson ed. (2011) for discussions of the nature of perception and the individuation of sensory modalities. See Hawley and MacPherson eds (2011) for a recent collection of essays on the nature of perceptual content.
} 
available to others, and so on, we already find ourselves in a modal space that incorporates those kinds of possibility, a realm where there is the potential to encounter things in the various ways we do. The same goes for our thought; when we think about something, we already find ourselves in that same space of possibilities. At least some of these types of possibility are integral to our sense of reality. For instance, if experience incorporated no sense of anything as practically or perceptually accessible to others, the distinction between something's being there and its being merely imagined would break down. Similarly, the sense that at least some things are 'practically accessible to me' arguably contributes to a grasp of what it is for something to be 'there'. The world thus takes the form of a "universal horizon", a space of possibilities that constitutes our sense of reality. Various passages in Husserl can be interpreted in ways that complement this view. For example, in the following passage, he seems to say that the world is presupposed by the intelligibility of our taking and not taking things to be the case:

It belongs to what is taken for granted, prior to all scientific thoughts and all philosophical questioning, that the world is - always is in advance - and that every correction of an opinion, whether an experiential or other opinion, presupposes the already existing world, namely, as a horizon of what in the given case is indubitably valid as existing, and presupposes within this horizon something familiar and doubtlessly certain with which that which is perhaps cancelled out as invalid came into conflict. (1970, p.110)

We find similar themes in the work of Merleau-Ponty, who refers to the world as "the horizon of horizons, the style of all possible styles" (1962, p.330). The same general point can be extracted from Heidegger's work too. In Being and Time, he claims that the kinds of 'mattering' or significant possibility that we are receptive to are symptomatic of how we find ourselves in the world [Befindlichkeit]. Being "affected by the unserviceable, resistant, or threatening character" of something is "ontologically possible only in so far as Being-in as such has been determined existentially beforehand in such a manner that what it encounters within-the-world can 'matter' to it" (1962, p.176). According to Heidegger, we can find ourselves in the world in various subtly and occasionally dramatically different ways, which he calls 'moods' [Stimmungen] (1962, p.176). ${ }^{6}$ Granted, there are many differences between these philosophers' positions. However, I suggest that, if we abstract away from various superficial disagreements, we find a deeper common ground here. Indeed, it is important that

\footnotetext{
${ }^{6}$ See Ratcliffe (in press) for a detailed discussion of Heidegger on mood.
} 
we do so - if the phenomenological tradition were characterised principally by a series of deep disagreements about the structure of experience, its lack of consensus would serve to undermine it. In short, why trust what phenomenologists say, when they can't even agree with each other? A central point of convergence, I propose, is the view that encountering entities in the ways we do depends upon being open to certain kinds of possibility, an openness that is inseparable from belonging to a 'world'. Hence the nature of the charge that naturalism overlooks the world becomes clearer: science concerns itself only with what is and is not the case, whereas the world is a modal space that is presupposed by the intelligibility of that distinction, amongst others. The 'world' that phenomenologists seek to describe 'is' in a quite different way to how the scientifically described world 'is'. The former is presupposed by the 'is'/'is not' distinction, rather than being something that falls into one or the other of the two categories. It therefore has a different kind of existential status. So the phenomenologists' complaint is not principally about naturalism's commitment to 'physicalism'. It is not about what kinds of worldly entities there are or what those entities are made up of; it is about recognising a phenomenological achievement that is presupposed by the intelligibility of any enquiry concerning what the world does and does not contain. And the nature of that achievement is made no clearer by attributing it to a non-physical worldly entity rather than a physical worldly entity. The position need not amount to a criticism of science: perhaps the 'world' of phenomenology is simply not its domain. However, it is critical of scientific naturalism, which regards the deliverances of science as exhaustive. The argument runs as follows:

1. Science is concerned only with revealing what is the case.

2. Naturalism restricts itself to what science delivers and thus to what is the case.

3. Therefore, naturalism fails to accommodate the space of possibilities presupposed by the intelligibility of something's being the case.

4. The space of possibilities is a phenomenological achievement.

5. Therefore, phenomenology cannot be naturalised.

\section{The Sense of Unreality}

Is the argument that I have pieced together a good one? The claim that science is only concerned with revealing 'what is the case' needs further clarification. On two readings, it is simply false. First of all, science is surely equally pre-occupied with what is only 'possibly the case' and what is 'not the case'. Second, science can acknowledge that the world 
incorporates possibilities. But both these points are consistent with the argument I have outlined. When science considers what is, what is not and what might be the case, it presupposes the intelligibility of a distinction between being, not being and possibly being the case. It is this intelligibility that is claimed to depend upon a presupposed phenomenological possibility space. And the question of whether the world explored by science ultimately does or does not incorporate possibility takes as given the intelligibility of a distinction between its being and not being the case that possibility is a constituent of scientifically described reality. The claim that the ability to draw that distinction presupposes a phenomenology of possibility is different from the claim that, when we consider what 'is', we find that it includes possibilities. However, there is surely another serious problem with the position I have sketched: it depends upon making a leap from a debatable theory of perceptual content to the claim that, in addition to experiencing token possibilities, there is an underlying phenomenology of kinds of possibility. And, even if that leap is defensible, the account rests upon a theory of perception that I have admitted to be questionable. So the naturalist could respond by challenging the claim that we experience possibilities, or the move from this to the view that the sense of reality is comprised of a phenomenological possibility space. However, although I think that a good way to explicate the latter is by approaching it through the former, I will now suggest that it is possible to argue directly for the 'possibility space' account of 'world' without first establishing that we experience token possibilities, thus weakening the force of both objections. In fact, I think there is a wealth of phenomenological support for the account: a vast body of first-person testimony is plausibly interpreted in terms of alterations in the kinds of possibility that people are receptive to, alterations that are inextricable from changes in the sense of reality. Furthermore, I have come across no other interpretive framework that can make sense of this testimony in a coherent, unifying way. Hence it is plausible to maintain that the sense of reality has a phenomenological structure along the lines sketched here.

One of the principal sources of evidence is the experience of psychiatric illness, as conveyed by many first-person reports. There has been around a century of interaction between phenomenology and psychopathology. Most of the work done in that tradition is consistent with the view that experience incorporates a changeable sense of reality, associated with a grasp of possibilities. ${ }^{7}$ Turning to first-person accounts of psychiatric illness, it is easy to see

\footnotetext{
${ }^{7}$ See Ratcliffe and Broome (in press) for further discussion of phenomenological psychopathology.
} 
why. In my 2008 book Feelings of Being, I offered a lengthy defence of the view that certain forms of psychiatric illness involve changes in a space of possibilities and thus in the sense of reality. It is debatable which kinds of experienced possibility do and which do not contribute to a sense of reality. My own view is that it implicates many kinds of possibility, and is thus susceptible to many different kinds of change (Ratcliffe, 2008, Chapter 7). However, my aim here is more modest than that of specifying exactly which kinds of possibility are involved and what effects their absence has. I want to offer a few examples of first-person reports of psychiatric illness, in order to illustrate how an 'argument from contrast' can be put together in support of the possibility space view. These reports are representative of a much more substantial body of testimony, which could be appealed to in order to further develop and defend the view. The fact that many people complain of something having been lost from experience suggests that, rather than the arrival of an anomalous experience where there was no experience before, there is a change in something that itself has a phenomenology Furthermore, that change is compellingly interpreted in terms of the kinds of possibility that they are receptive to.

One advantage of the appeal to a phenomenology of possibility is that it can account for seemingly paradoxical experiential changes, where everything is said to look exactly the same and yet very different. Take the case of delusional atmosphere or delusional mood, as described by Karl Jaspers:

Patients feel uncanny and that there is something suspicious afoot. Everything gets a new meaning. The environment is somehow different - not to a gross degree - perception is unaltered in itself but there is some change which envelops everything with a subtle, pervasive and strangely uncertain light. A living-room which formerly was felt as neutral or friendly now becomes dominated by some indefinable atmosphere. Something seems in the air which the patient cannot account for, a distrustful, uncomfortable, uncanny tension invades him. (Jaspers, 1962, p.98)

How can everything look so different, when none of the perceived properties have changed? One answer is that the possibilities offered by things have changed. A nearby object that lacked the possibility of 'tangibility' would look oddly distant, perhaps not there. Similarly, a room that appeared threatening would look different from one that looked homely and welcoming, even if there were no alteration in an inventory of perceived entities and their 
properties. However, that an approach has explanatory power does not make it right. Furthermore, even if delusional atmosphere is to be accounted for in this way, it is not clear whether it involves a reconfiguration of token properties or of property types. However, the 'types of possibility' interpretation receives further support when we turn to first-person descriptions of experiences of schizophrenia. Consider the well-known account offered by 'Renee' in Autobiography of a Schizophrenic Girl. She reports a complete loss of practical significance from the world, with the result that everything looked strange and distant nothing appeared 'real' in the way things previously did:

Everything was exact, smooth, artificial, extremely tense; the chairs and tables seemed models placed here and there. Pupils and teachers were puppets revolving without cause, without objective. I recognized nothing, nobody. It was as though reality, attenuated, had slipped away from all these things and these people. (Sechehaye, 1970, p.27)

As Renee puts it, she "lost the feeling of practical things" (Sechehaye, 1970, p.29). However, it is not simply that the sense of reality was altogether gone from her experience, that the distinction between being and not being the case was completely absent. Rather, the sense of reality had changed; things did not appear to be the case in the way they once did. Renee expresses this by contrasting the more usual experienced reality of things with their 'existing':

When, for example, I looked at a chair or a jug, I thought not of their use or function - a jug not as something to hold water and milk, a chair not as something to sit in - but as having lost their names, their functions and meanings; they became 'things' and began to take on life, to exist. (Sechehaye, 1970, pp.55-6)

Such reports indicate that a diminution or perhaps even loss of receptiveness to a certain kind of possibility, in this case practical significance, can amount to an all-pervasive phenomenological change and, with it, an altered sense of reality. The same applies to a loss of interpersonal possibilities. This is equally evident from other parts of Renee's account, and also from many others. Consider, for example, an account offered Stephen Weiner, who describes being troubled by derealisation symptoms for most of his life: 
....the houses in my neighbourhood seemed one-dimensional - they seemed as though they were painted, as though I could stick my hand or an object through them. Colors seemed less bright as well - but I hardly had words for all this at the time: it was an overwhelmingly preverbal feeling, but I found some words for it. (Weiner, 2003, p.369) ${ }^{8}$

This is consistent with the view that perceptual experience is shaped by certain kinds of possibility. The perceived lack of dimensionality is related to the possibility of sticking one's hand straight through things; they fail to offer the usual range of perceptual opportunities associated with nearby three-dimensional entities. As Renee similarly says, things looked "artificial", an experience that might be conveyed in terms of their being replicas or fakes (which might similarly lack certain possibilities associated with the genuine object) or in terms of their not being real or fully there. Weiner goes on to report how he once asked a psychiatrist whether he had ever thought everything might be illusory. Just asking the question, he recalls, "produced a chilling feeling that he [the psychiatrist] did not exist" (2003, p.370). More generally, Weiner's world became somehow solipsistic; it lacked an ordinarily taken-for-granted sense of availability to others. His account thus suggests a loss of certain kinds of possibility from experience, including possibilities for perceptual and/or practical accessibility and possibilities for others. Closely associated with this, he remarks, is erosion of a sense of reality and, with it, a sense that anything might be worthwhile:

I certainly feel that my experience of derealisation has had great consequences for my ability to make plans and carry them out, not because I slide into incongruous and discontinuous ego states, but because the worth of any endeavour is always being called into question by my strong feelings of solipsistic despair. This feeling has almost, I must admit, attained the status of a form conviction, that because nothing truly exists, all effort is futile. (2003, p.371)

Although I have focused on schizophrenia here in order to illustrate how the claim that we experience ourselves as inhabiting a possibility space might be defended, it is worth stressing that changes in the sense of reality are certainly not exclusive to schizophrenia. They also occur in a range of other psychiatric conditions. For example, people diagnosed with forms of depression often report that they reside in a different 'world' or that they are irrevocably cut off from the world. Typical complaints include the following:

\footnotetext{
${ }^{8}$ Weiner has received various diagnoses over the years, the most recent being paranoid schizophrenia and schizo-affective disorder (Weiner, 2007)
} 
"I feel like I am watching the world around me and have no way of participating."

"I feel as if I am in a bubble, like being in a film."

“...the world seems to be happening around you. [....] It's like on TV when the main character stands still and they fast forward the street scene of people milling around them." 9

Amongst other things, the world is devoid of practically significant or enticing possibilities for oneself. Everything and everyone seem oddly distant, detached, not quite 'there'. However, changes in the sense of reality and belonging are not, in my view, restricted to experience of psychiatric illness. It is plausible to maintain that most or all of us experience 'wobbles' in the sense of reality from time to time. Such experiences are often very hard to describe, and many of them lack established names. ${ }^{10}$ Some are most frequently communicated in terms of their causes. For example, we talk of jetlag, a bad hangover or the experience of flu. Hence successful reference is achieved without recourse to detailed phenomenological description, or indeed to any such description. But such experiences can also be characterised in terms of a 'world' that lacks something or seems somehow different, in a way that shapes all of one's experiences and thoughts. And I suggest that they too can be described phenomenologically in terms of the kinds of possibility that one is open to. Of course, one could still refuse to interpret all of the testimony alluded to here in such a way as to support the phenomenological conception of 'world'. However, I think that, when considered as a whole, the body of testimony is compelling enough to lend considerable weight to the phenomenologists' position.

\section{Conclusion}

If the account of world that I have briefly sketched here is along the right lines, then naturalism has overlooked something important. In short, attempts to naturalise human experience lack sufficient appreciation of what it is that they seek to naturalise. Although many different characterisations of human experience or 'phenomenal consciousness' inform naturalistic projects, I know of none that clearly acknowledge the aspect of experience that the phenomenologists seek to make explicit. McGinn (1989, p.349) summarises the problem for naturalism with the oft-quoted question "how can technicolor phenomenology arise from soggy gray matter?" However, if what I have suggested is right, the question needs to be

\footnotetext{
9 These are responses to a questionnaire study that I recently carried out with colleagues. See Ratcliffe (forthcoming) for a detailed phenomenological discussion of depression and the sense of reality, which includes a defence of the view that depression involves changes in a phenomenological possibility space.

${ }^{10}$ However, there are many elaborate descriptions to be found in good literature (Ratcliffe, 2008, Chapter 2).
} 
reformulated in this rather more complicated and inelegant way: how can an inventory of what 'is' accommodate an experienced possibility space that is presupposed by the intelligibility of what is, a space that is surely attributable to 'consciousness' but presents itself as the shared world that we find ourselves in, rather than as something originating in a subjective perspective? Alternatively, one might regard the latter question as simply different from McGinn's, in which case the naturalist has failed to acknowledge an aspect of experience, rather than misconstrued it.

Hence the phenomenologists' case against naturalism does, I think, make plausible the conclusion that naturalistic explanations of human experience are impoverished, confused or - perhaps - both. However, this does not imply the rejection of naturalism. The naturalist could concede that the conceptions of human experience she has been working with are inadequate, and thus attempt to re-characterise what it is she seeks to naturalise. But there is a further problem for her to deal with. What the naturalist also needs is some argument to the effect that the methods and deliverances of scientific enquiry ultimately have priority over those of phenomenological enquiry. It may well be coherent to maintain that a scientific picture of what is the case should aspire to include an account of how the sense of reality that allows us to operate with an 'is'/'is not' distinction originates. Then again, it is just as coherent for the phenomenologist to maintain that a scientific picture of things can be assimilated by a more encompassing phenomenological account of how we find ourselves in the world. ${ }^{11}$ As the space of possibilities revealed by phenomenology has not yet been acknowledged by the naturalist, we do not currently have the required argument in support of naturalism.

Acknowledgements: Many thanks to an audience at the August 2011 Royal Institute of Philosophy conference on 'Human Experience and Nature' for some very helpful comments and criticisms.

\section{References}

Dennett, D. C. 1987. The Intentional Stance. Cambridge MA: MIT Press.

Dupré, J. 2001. Human Nature and the Limits of Science. Oxford: Clarendon Press.

Gallagher, S. and Zahavi, D. 2008. The Phenomenological Mind. London: Routledge.

\footnotetext{
${ }^{11}$ The case for such a view could start by emphasising that the subject matter of phenomenology is not 'subjective' in a way that sets it apart from that of 'objective' scientific enquiry - what it reveals is not experienced as 'mine' but as a possibility space that is not just mine, a space that is presupposed by the objective world of the naturalist.
} 
Hawley, K. and MacPherson, F. 2011. The Admissible Contents of Experience. Oxford: WileyBlackwell.

Heidegger, M. 1962. Being and Time. Trans. Macquarrie, J. and Robinson, E.. Oxford: Blackwell.

Heidegger, M. 2001. Zollikon Seminars: Protocols - Conversations - Letters. Ed. Boss, M.; Trans. Mayr, F. and Askay, R. Evanston: Northwestern University Press.

Husserl, E. 1960. Cartesian Meditations: An Introduction to Phenomenology. Trans. Cairns, D. The Hague: Martinus Nijhoff.

Husserl, E. 1970. The Crisis of European Sciences and Transcendental Phenomenology. Trans. Carr, D. Evanston: Northwestern University Press.

Husserl, E. 1973. Experience and Judgment. Trans. Churchill, J. S. and Ameriks, K. London: Routledge.

Husserl, E. 1989. Ideas Pertaining to a Pure Phenomenology and to a Phenomenological Philosophy: Second Book. Trans. Rojcewicz, R. and Schuwer, A. Dordrecht: Kluwer.

Husserl, E. 2001. Analyses concerning Passive and Active Synthesis: Lectures on Transcendental Logic. Trans. Steinbock, A. J. Dordrecht: Kluwer.

Jaspers, K. 1962. General Psychopathology. Trans. Hoenig, J. and Hamilton, M. W. Manchester: Manchester University Press.

MacPherson, F. ed. 2011. The Senses: Classic and Contemporary Philosophical Perspectives. Oxford: Oxford University Press.

McGinn, C. 1991. The Problem of Consciousness. Oxford: Blackwell.

Merleau-Ponty, M. 1962. Phenomenology of Perception. Trans. Smith, C. London: Routledge.

O'Callaghan, C. 2011. Lessons from beyond Vision (Sounds and Audition). Philosophical Studies 153: $143-160$.

O'Callaghan, C. forthcoming. Perception and Multimodality. In Margolis, E., Samuels, R. and Stich, S. eds. Oxford Handbook to Philosophy and Cognitive Science. Oxford: Oxford University Press.

Ratcliffe, M. 2008. Feelings of Being: Phenomenology, Psychiatry and the Sense of Reality. Oxford: Oxford University Press.

Ratcliffe, M. in press. Why Moods Matter. In Wrathall, M. ed. Cambridge Companion to Being and Time. Cambridge: Cambridge University Press.

Ratcliffe, M. forthcoming. The Modalities of Melancholy: A Phenomenological Study of Depression. Oxford: Oxford University Press.

Rouse, J. 2002. How Scientific Practices Matter: Reclaiming Philosophical Naturalism. Chicago: University of Chicago Press.

Roy, J-M., Petitot, J., Pachoud, B. and Varela, F. J. 1999. Beyond the Gap: an Introduction to Naturalizing Phenomenology. In Petitot, J., Varela, F. J., Pachoud, B. and Roy, J-M. eds. Naturalizing Phenomenology: Issues in Contemporary Phenomenology and Cognitive Science. Stanford: Stanford University Press: 1-80. 
Sass, L. A. 1994. The Paradoxes of Delusion: Wittgenstein, Schreber, and the Schizophrenic Mind. Ithaca: Cornell University Press.

Sechehaye, M. 1970. Autobiography of a Schizophrenic Girl. New York: Signet.

Thagard, P. 2002. The Passionate Scientist: Emotion in Scientific Cognition. In Carruthers, P., Stich, S. and Siegal, M. eds. The Cognitive Basis of Science. Cambridge: Cambridge University Press: 235250 .

Van Fraassen, B. 2002. The Empirical Stance. New Haven: Yale University Press.

Weiner, S. 2003. Unity of Agency and Volition: Some Personal Reflections. Philosophy, Psychiatry \& Psychology 10: 369-372.

Weiner, S. 2007. Lack of Autonomy: A View from the Inside. Philosophy, Psychiatry \& Psychology 14: 237-238.

Wheeler, M. (2005) Reconstructing the Cognitive World: The Next Step. Cambridge MA: MIT Press. 